\title{
Prevalence of skin disorders among primary-school children in Baghdad governorate, Iraq
}

\author{
K.A. Khalifa, ${ }^{1}$ T.S. Al-Hadithi, ${ }^{2}$ F.H. Al-Lami ${ }^{2}$ and J.K. Al-Diwan ${ }^{2}$
}

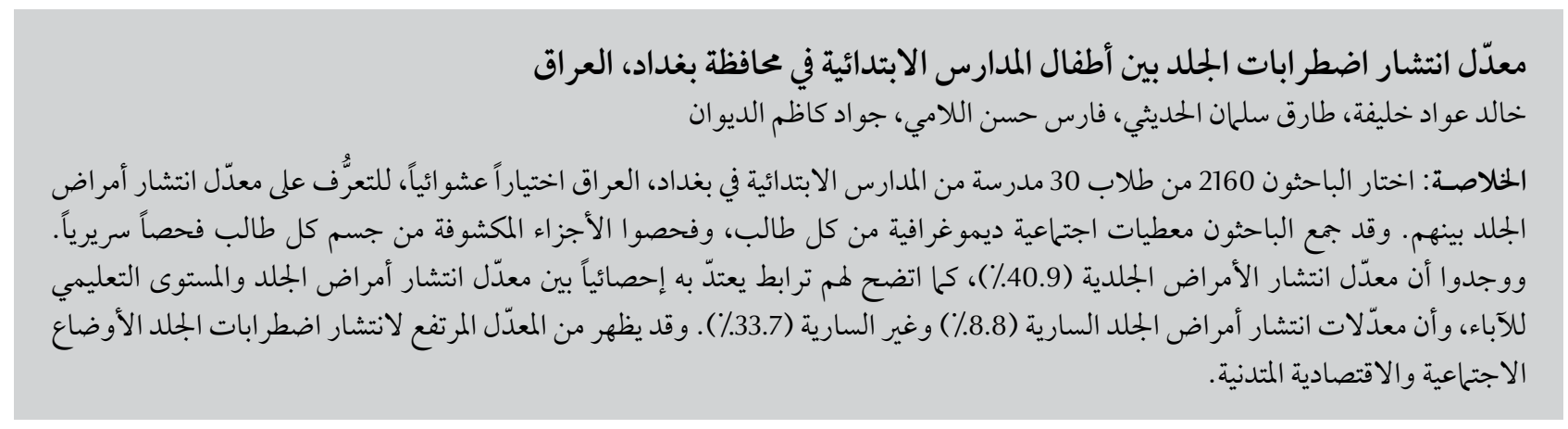

ABSTRACT To determine the prevalence of skin diseases among primary-school children in Baghdad, Iraq, a total of 2160 schoolchildren were randomly selected from 30 primary schools. Sociodemographic data were collected from each pupil and exposed parts of the body of each child were clinically examined. The overall prevalence of skin diseases was $40.9 \%$. A significant association between the prevalence of skin diseases with education level of parents was demonstrated. The prevalence rates of transmissible and nontransmissible skin diseases were 8.8\% and $33.7 \%$ respectively. The high prevalence rate may reflect prevailing low socioeconomic conditions.

\section{Prévalence des affections cutanées parmi les enfants d'école primaire du gouvernorat de Bagdad, Iraq}

RÉSUMÉ Afin de déterminer la prévalence des affections cutanées parmi les enfants des écoles primaires à Bagdad (Iraq), 2160 écoliers ont été sélectionnés au hasard dans 30 écoles. Les données socio-démographiques ont été recueillies auprès de chaque élève et les parties du corps exposées de chacun d'entre eux ont été examinées sur le plan clinique. La prévalence globale des affections cutanées était de 40,9\%. Une association significative entre la prévalence des affections cutanées et le niveau d'éducation des parents a été établie. Le taux de prévalence des affections cutanées contagieuses et non contagieuses était de 8,8 \% et 33,7 \% respectivement. Ce taux de prévalence élevé peut refléter les mauvaises conditions socio-économiques observées dans le pays. 


\section{Introduction}

Skin diseases are a major health problem affecting a high proportion of the population and causing distress and disability [1]. They are more frequent among primary-school children in both developing and industrialized countries [2]. Unfortunately, no previous study concerning the overall burden of skin diseases among primary-school children in Baghdad, Iraq, has been carried out. However, studies on the prevalence of pediculosis $[3,4]$ and atopic dermatitis [5] are available. A prevalence of $31.8 \%$ of skin diseases among students was reported in Basra,, Iraq [6].

This study was designed to determine the prevalence of skin diseases among primary-school children in Baghdad, and to describe their association with various sociodemographic factors such as age, sex, residence and education level of parents.

\section{Methods}

This cross-sectional survey was conducted from 10 February to 26 April 2004.

A multi-stage, stratified sample of 2160 schoolchildren from 30 primary schools in Baghdad governorate was randomly selected for the study. In the first sampling stage primary schools were classified into 4 groups according to sex and residence. They were categorized into urban male schools, urban female schools, rural male schools, and rural female schools. Then using the appropriate allocation method of sampling, 20 schools were randomly selected from the urban groups and 10 schools from the rural schools. In the second sampling stage 12 pupils were selected from each grade by simple random sampling. Sample size was determined using a confidence level of $95 \%$, with $10 \%$ degree of precision of the expected proportion and an estimated prevalence of $16 \%$.
A self-administered, closed-ended questionnaire was designed by the researchers. The questionnaire was subjected to a pilot trial on 50 children before it was distributed in its final form. Analysis revealed that the questionnaire was consistent, reliable and easy to answer. Then the questionnaire form was distributed to each selected pupil to be answered by his parents. Verbal consent was obtained from the children, who were asked to bring written consent from their parents for participation in the study. All questionnaires were returned with completed responses. Data collected included general sociodemographic information such as age, sex, residence (urban or rural), number of household members, number of rooms and educational level of parents. Household crowding index was calculated by dividing the number of household members by the number of rooms.

The exposed parts of the body of each child were clinically examined by a consultant dermatologist and the dermatological findings were recorded. Wood's light examination was used to confirm the diagnosis of tinea capitis, pityriasis versicolor and vitiligo. Skin diseases were classified into transmissible and nontransmissible diseases according to the classification adopted by other workers $[7,8]$. Transmissible skin diseases were categorized into bacterial (impetigo and boils), viral (herpes simplex and warts), superficial mycotic (tinea versicolor and tinea capitis) and parasitic infections (pediculosis capitis). Nontransmissible diseases included dermatitis/eczema (eczema, atopic dermatitis, pityriasis alba, lip-licking dermatitis), skin appendages disorders (alopecia areata, hypertrichosis, acne vulgaris), papillosquamous disorders (psoriasis, lichen nitidus, lichen planus, pityriasis rubra pilaris, ichthyosis), pigment disorders (vitiligo, freckles, naevi) and insect bites.

The chi-squared test was used for statistical analysis. $P \leq 0.05$ was considered statistically significant.

\section{Results}

The age of selected pupils ranged between 6 and 15 years, with a mean age of 9.1 (standard deviation 3.6) years and a male to female ratio of $0.97: 1$.

Skin disorders were noted in 883 children, giving an overall prevalence of $40.9 \%$. There was no significant association between the prevalence of skin diseases and age $(P=0.06)$, sex $(P$ $=0.74)$, residence $(P=0.06)$ or crowding index $(P=0.42)$ (Table 1). The education level of parents was significantly associated with the prevalence of skin diseases $(P=0.04)$.

The prevalence rates of transmissible and nontransmissible skin diseases were $8.8 \%$ and $33.7 \%$ respectively. Analysis of association of both categories with age revealed that there was a gradual, nonsignificant $(P=0.68)$ decline in the prevalence of transmissible skin diseases with increasing age, while there was a significant $(P<0.001)$ increase in the prevalence of nontransmissible skin diseases with age (Figure 1).

\section{Discussion}

Thisstudy revealed an overall prevalence of skin diseases of $40.9 \%$. This is higher than the previously reported prevalence (33.5\%) among older students in Baghdad in 1987 [9]. This difference could be attributed to a decline in the general socioeconomic conditions of most groups of Iraqi people and a deterioration in the health and teaching services, and consequently a lack of cooperation between health and teaching authorities which followed the 1991 Gulf War, economic sanctions and the invasion of Iraq by Allied Forces in 2003, with the accompanying internal conflict. However, this rate is higher than that reported among primary-school children in Basrah, Iraq in 2004 (31.8\%) [6]. It is twice than that reported in Jordan (19.3\%) [10] and slightly higher than in Malaysia (34.4\%) [11] and 


\begin{tabular}{|c|c|c|c|c|}
\hline $\begin{array}{l}\text { Table 1 Prevalence of } s \\
\text { variables }(\boldsymbol{n}=\mathbf{2 1 6 0})\end{array}$ & ses in relatic & to selec & ciodemc & iphic \\
\hline Variable & Total & Positi & disease & $P$-value \\
\hline & No. & No. & $\%$ & \\
\hline Age (years) & & & & \\
\hline $6-7$ & 681 & 255 & 37.4 & \\
\hline $8-9$ & 652 & 264 & 40.5 & \\
\hline $10-11$ & 583 & 251 & 43.1 & \\
\hline $12-15$ & 244 & 113 & 46.3 & 0.06 \\
\hline Sex & & & & \\
\hline Male & 1066 & 432 & 40.5 & \\
\hline Female & 1094 & 451 & 41.2 & 0.74 \\
\hline Residence & & & & \\
\hline Urban & 1440 & 568 & 39.4 & \\
\hline Rural & 720 & 315 & 43.8 & 0.06 \\
\hline Household crowding & & & & \\
\hline$\leq 3$ & 1440 & 580 & 40.3 & \\
\hline$>3$ & 720 & 303 & 42.1 & 0.42 \\
\hline Education level offat & & & & \\
\hline Illiterate & 67 & 31 & 46.3 & \\
\hline Primary school & 648 & 272 & 42.0 & \\
\hline Secondary school & 1008 & 427 & 42.4 & \\
\hline Higher education ${ }^{a}$ & 437 & 153 & 35.0 & 0.04 \\
\hline Education level of mo & & & & \\
\hline Illiterate & 278 & 114 & 41.0 & \\
\hline Primary school & 953 & 413 & 43.3 & \\
\hline Secondary school & 758 & 301 & 39.7 & \\
\hline Higher education ${ }^{a}$ & 171 & 58 & 33.9 & 0.04 \\
\hline Total & 2160 & 883 & 40.9 & \\
\hline
\end{tabular}

${ }^{a}$ Diploma and BSc degrees and graduate qualifications.

Nigeria (35.2\%) [12]. The rate is lower than that reported in Turkey (49.3\%) [13] and much lower than in Ethiopian schoolchildren (96.8\%) [14]. These variations in the prevalence of skin diseases may be related to genetic and racial differences, social and hygiene factors, nutrition status, climate factors, state of industrialization, age structure of the study sample and other socioeconomic factors [15].

Our finding that there was no significant association between the prevalence of skin diseases and age is in agreement with previous reports on primary-school children in Iraq [6] and Romania [16]. No significant sex variations in the prevalence of skin diseases
[18]. In both these countries skin diseases were more prevalent in rural than urban areas. A higher prevalence of skin diseases among children living in homes with a high crowding index was shown in our study, but the difference was not significant. However, a significant association between prevalence rates of skin diseases and crowding index was reported in Turkey [13]. The significant association of skin diseases with education level of parents was expected as low education contributes to a low socioeconomic status of the family. In Basrah, Iraq, a high prevalence of skin diseases in regions of low socioeconomic status was reported [6]. High prevalence rates were also reported in poor developing countries, which may reflect prevailing low socioeconomic conditions in such areas $[7,14,19,20]$.

In this study the prevalence of transmissible skin diseases was $8.8 \%$, which is lower than that previously reported in Basrah, Iraq (12.6) [6] and Turkey (16.2\%) [13]. High rates varying between $50 \%$ and $60 \%$ were reported in Ethiopia [7] and Ghana [21]. Rates of $28.8 \%$ and $20.3 \%$ were reported among blind and deaf pupils respectively in Saudi Arabia [1]. These differences may be attributed to variations in personal and environmental hygiene and degree of exposure.

The prevalence of nontransmissible skin diseases was $33.7 \%$, which is lower than that reported in Saudi Arabia $(82.3 \%)[1]$ and Turkey $(57.5 \%)$ [13]. However, it is higher than that reported in Hong Kong (27\%) [22]. These variations may be due to differences in the way the clinical examination was carried out, i.e. whether it covered only the exposed parts of the body or the whole body. Other factors, e.g. racial and genetic differences, may also contribute to these variations.

The decline in the prevalence of transmissible skin diseases with age may be attributed to better personal hygiene and health care practised by 


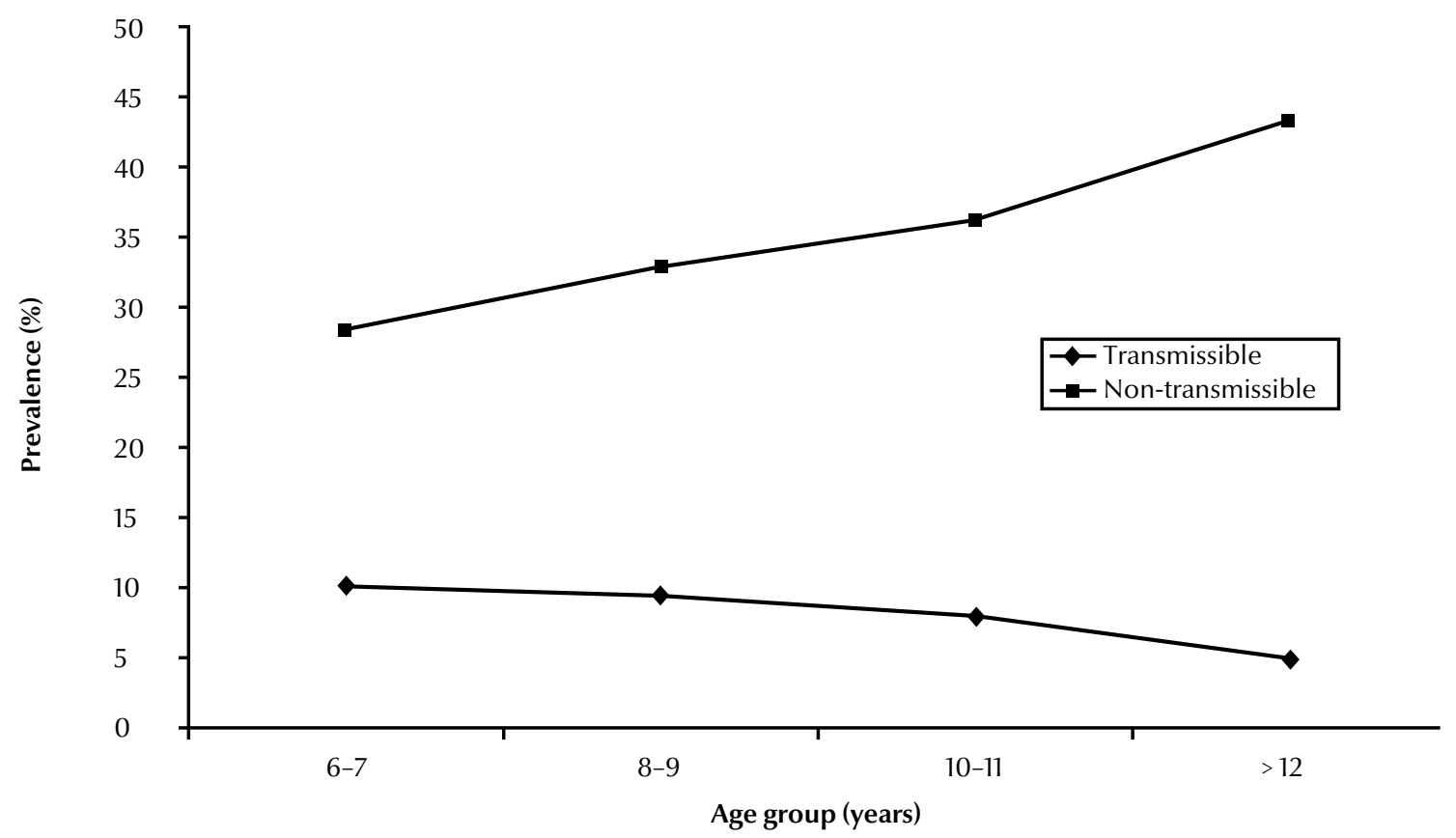

Figure 1 Prevalence of transmissible and nontransmissible skin diseases among primary-school children by age group

older school children. Other workers reported a similar trend in some transmissible diseases such as tinea capitis and pediculosis capitis in Iraq [4,23-25] and in other countries [14,26-29]. On the other hand, the significant increase in the prevalence of nontransmissible skin diseases with age may be due to increased exposure to environmental pollutants, chemicals and allergens. In addition, the reduction in the prevalence of transmissible diseases as a consequence of improvements in personal hygiene and environmental sanitation may have contributed to the increase in the prevalence of nontransmissible diseases [30]. Similar findings have been reported in Iraq [6] and other countries $[13,16,31]$.

This study indicates that skin disorders are very common among primary-school children in Baghdad governorate, which may reflect prevailing low socioeconomic conditions and a poor level of awareness of these diseases or their health implications by parents and teachers. Improved school health programmes would lead to a decline in the prevalence of such disorders among schoolchildren. Routine inspection of pupils for skin disorders by their teachers and school health personnel should be incorporated in such a programme.

\section{References}

1. Abolfotouh MA, Bahamadan K. Skin diseases among blind and deaf male students in southwestern Saudi Arabia. Annals of Saudi medicine, 2000, 20:161-9.

2. Laughter $\mathrm{D}$ et al. The prevalence of atopic dermatitis in Oregon school children. Journal of the American Academy of Dermatology, 2000, 34:649-55.

3. Hassan AT. A study of the prevalence of pediculosis capitis among primary school children [diploma dissertation]. Baghdad, Iraq, Faculty of Medicine, Al-Mustansiriya University, 2000.

4. Al-Kubaisy WA, Al-Rubauie MG, Al-Rawi JR. The prevalence of head louse among primary school pupils in Baghdad city. Journal of the Faculty of Medicine Baghdad, 1994, 36:665-70.

5. Jassim RK. Prevalence of atopic dermatitis among primary school children in Baghdad, Al-Karkh district [MSc thesis]. Baghdad, Iraq, Faculty of Medicine, Al-Mustansiriya University, 2004.

6. Al-Rubaiy KK, Habib OS, Ebrahim S. Pattern of skin diseases among primary school children in Basrah, southern Iraq. Medical journal of Basrah University, 2004, 1-2:40-2.
7. Dagnew MB, Erwin G. Epidemiology of common transmissible skin diseases among primary school children in north-west Ethiopia. Tropical and geographical medicine, 1991, 43:152-5.

8. Bahmadan $\mathrm{K}$ et al. Skin infection among adolescent boys in Abha, Saudi Arabia. International journal of dermatology, 1996, 35:405-7.

9. Abdul Hussain HM. Morbidity rates of skin diseases in Baghdad city [diploma dissertation]. Baghdad, Iraq, Faculty of Medicine, Baghdad University, 1987.

10. Shakkoury WA, Abu-Wandy E. Prevalence of skin disorders among male school children in Amman, Jordan. Eastern Mediterranean health journal, 1999, 5:955-9.

11. Mahe A et al. Skin diseases of children in Mali: a public health problem. Transactions of the Royal Society of Tropical Medicine and Hygiene, 1995, 89:467-70.

12. Ogunbiyi AO, Owoaje E, Ndahi A. Prevalence of skin disorders in school children in Ibadan, Nigeria. Pediatric dermatology, 2005, 22:6-10. 
13. Inanir I et al. Prevalence of skin conditions based on socioeconomic factors. Pediatric dermatology, 2002, 19:307-11.

14. Figueroa JI et al. Tinea capitis in southwestern Ethiopia: a study of risk factors and carriage. International journal of dermatology, 1997, 36:661-6.

15. Parthasadhi P, Al-Gufai AF. The pattern of skin diseases in Hail region, Saudi Arabia. Annals of Saudi medicine, 1999, 8:558-61.

16. Popescu R et al. Prevalence of skin conditions in Romanian school children. British journal of dermatology, 1999, 140:891-6.

17. Al-Hasawi NA, Al-Saleh QFA. A prospective survey of paediatric dermatology clinic patients in Kuwait: an analysis of 10000 cases. Pediatric dermatology, 1999, 16:6-11.

18. Wa YH, Su HY, Hsieh YJ. Survey of infectious skin diseases and skin infestation among primary school students in Taitong county, eastern Taiwan. Journal of the Formosa Medical Association, 2000, 99:128-34.

19. Figueroa Jl et al. The prevalence of skin diseases among school children in rural Ethiopia: a preliminary assessment of dermatologic need. Pediatric dermatology, 1996, 13:378-81.

20. Gibbs S. Skin diseases and socioeconomic conditions in rural Africa, Tanzania. International journal of dermatology, 1996 35:633-9.

21. Acheampong JW et al. Scabies and streptococcal skin infection in Ghana. Tropical doctor, 1998, 18:151-3.
22. Fung WK, Lo KK. Prevalence of skin diseases among school children and adolescents in a student health service in Hong Kong. Pediatric dermatology, 2000, 17:440-6.

23. Al-Mousawi T, Al-Affas NH, Al-Ramahyi AK. The incidence of scalp fungal infection among primary pupils in Basrah city. Iraqi journal of community medicine, 1993, 6:31- 6.

24. Fathi HI, Al-Samarai AM. Tinea capitis in Iraq: laboratory results. Eastern Mediterranean health journal, 2000, 6:138-48.

25. Al-Affas NH. Incidence of head louse (pediculosis humanus capitis) among pupils of two schools in Basrah city. Iraqijournal of community medicine, 1993, 6:31-4.

26. Oyeka CA. Tinea capitis in Awka local government area in Anambra state. West African journal of medicine, 1990, 9:120-3.

27. Sinniah B, Sinniah D, Rajeswari B. Epidemiology and control of human head louse in Malaysia. Tropical geographical medicine, 1988, 83:1300-3.

28. Elhan K, Budak S, Guraz AY. Pediculosis humanus capitis among the students of a secondary school in Kansiyaki-Izmir, Turkey. Journal of the Egyptian Society of Parasitologists, 1997, 27:157-61.

29. Amr ZS, Nusier MN. Pediculosis capitis in northern Jordan. International journal of dermatology, 2000, 39:919-21.

30. Howarth E. Is allergy increasing? -early life influences. Clinical and experimental allergy, 1998, 28(Suppl 6):2-7.

31. Dogra S, Kumar B. Epidemiology of skin diseases in school children: a study from northern India. Pediatric dermatology, 2003, 20:470-3.

\section{Ultraviolet radiation and human health}

Fact sheet $N^{\circ}$ 305, December 2009, available at: http://www.who.int/mediacentre/factsheets/fs305/en/index.html

Small amounts of UV radiation are beneficial to health and play an essential role in the production of vitamin D. However, excessive exposure to UV radiation is associated with different types of skin cancer, sunburn, accelerated skin ageing, cataract and other eye diseases. There is also evidence that UV radiation reduces the effectiveness of the immune system.

Children and adolescents are particularly vulnerable to the harmful effects of UV radiation. Excessive sun exposure in children is likely to contribute to skin cancer in later life. The mechanisms are unclear, but it may be that skin is more susceptible to the harmful effects of UV radiation during childhood. 